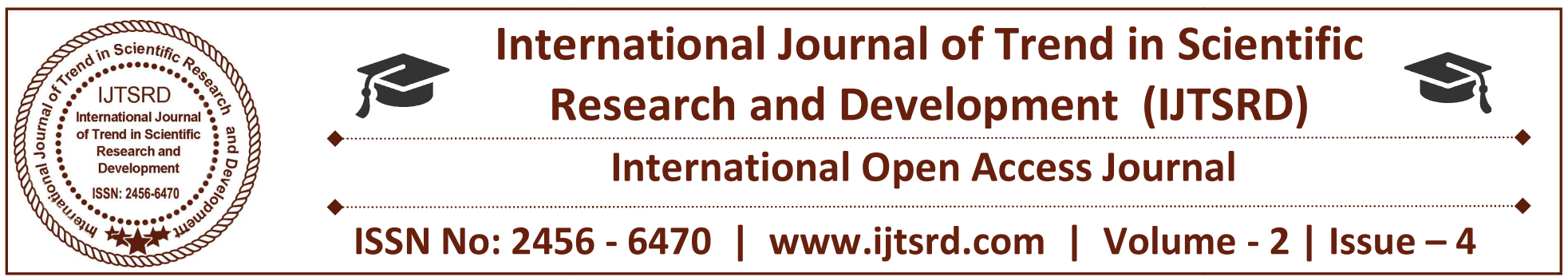

\title{
A Study on Evaluation and Effectiveness of Herbal Hand Sanitizer and its Anti Bacterial Activity
}

\author{
Dr. R. Kalaivani ${ }^{1}$, Ms. S. V. Bakiyalakshmi ${ }^{2}$, P. Arulmozhi ${ }^{3}$ \\ ${ }^{1,2}$ Assistant Professor, ${ }^{3}$ Research Scholar \\ PG \& Research Department of Botany \& Biotechnology, \\ Bon Secours College for Women, Thanjavur, Tamil Nadu, India
}

\section{ABSTRACT}

An ever increasing number of customers might want Good hygiene is a minister to health, comfort, and social interactions. Current society is well aware of hygiene. Washing hands is one of the simplest, most effective ways to get rid of germs and avoid infection. Transient microorganisms can be of any type, from any source may contact the body. As hands carry out the majority of functions of the human's body and are exposed to a variety of substances, hands hygiene plays a chief conscientiousness. Herbal plants are the unique resources of every country with potent medicinal properties pave ways towards sustainable health. In this present study, the combination of Trachyspermum copticum, Coleus aromaticus, Acorus calamus, Mentha piperita, Piper nigram, Elatteria cardamomum and Aloe barbadensis were used to formulate herbal hand sanitizer. The hand wash samples were subjected to microbial analysis. The isolated strains (Yersinia, Proteus, Escherichia coli, Klebsiella, Salmonella, and Pseudomonas) were characterized by their cultural characterization and confirmed using selective media. Herbal sanitizer possesses vitamin $\mathrm{C}(.4 \%)$, vitamin $\mathrm{A}(0.062)$ and considerable microbial load. The antioxidant activity was found to be $49 \%$ and the susceptibility test showed more activity found in Yersinia sp. $>$ Proteus sp $>$ Salmonella sp. $>$ Klebseilla sp. $>$ Pseudomonas sp. $>$ E.coli.

Keywords: Hygiene, Hand sanitizer, Anti microbial and Anti oxidant

\section{INTRODUCTION}

The Hands are the chief mode of transmission of microbial infections and diseases [1]. Hygiene of hands is hence the most vital thing to avoid the transmission of harmful germs and prevent the infections. Hand hygiene is the simplest and least expensive means of preventing nosocomial infections [2]. Hand-washing is significant in food production, food iservice and also chief in healthcare setting, homes and day care preparations. Though good \& simple hygiene technique is single most important, easy and least expensive means of preventing health care-associated infections and the spread of antimicrobial multidrug resistance; but, unfortunately poor hand-hygiene practices are still observed due to lack of scientific knowledge, unawareness of risks and unavailability of hand hygiene facilities[3].

Plant extracts and products have been used for centuries in traditional medicine, functional food, natural dyes, cosmetics, and in the treatment of diseases $[4,5,6]$. The lead advantage of using natural source is that they are easily available, cheap and harmless without side effects compared to chemical products. Plants have been used for long time by traditional healers to prevent or cure infectious conditions. As plants are rich in wide variety of secondary metabolites such as tannins, terpenoids, alkaloids, and flavonoids etc., they have been found to possess antimicrobial properties. Thus research has been increased enormously focusing on the production of natural products with improved quality. The emergence of bacterial resistance to the presently 
available antimicrobial drugs necessitates additional research in the discovery of new safe and effective antimicrobial agents.

Hands are needed to protect from bacterial pathogens as they are the most exposed part of the body. Proper hand hygiene is the most important measure of preventing health care associated infections especially children and old aged persons with less immunity. In present study we formulate herbal hand wash using different alcoholic plant extracts holds that antimicrobial potency and thereby formulating ready to use herbal hand sanitizer.

\section{MATERIALS AND METHODS}

\subsection{Plant Sample}

Trachyspermum copticum (Omum seed)

Coleus aromaticus (Karpooravalli)

Acorus calamus (Sweet flag; Vasambu)

Mentha piperita (Peppermint)

Piper nigram (Milagu)

Elatteria cardamomum (Ellam)

Aloe barbadensis (Aloe)

\subsection{Preparation of Herbal Hand Sanitizer:}

- The dried plant extracts (T. copticum, A.calamus, P. nigrum, E. Cardamomum, $C$. aromaticus and $M$. piperita) were prepared using methanol.

- Plant extracts T. copticum (3\%), A. calamus (1\%), P. nigrum (5\%), E. cardamomum (2\%) C. aromaticus (3\%) and M. piperita (5\%) were added in to the $100 \mathrm{ml}$ beaker.

- $15 \%$ of Aloe barbadensis was added in to the above extracts then $30 \%$ of methanol and $10 \%$ Almond aqueous were added then the solution was mixed by using stirrer.

- Finally citric acid (preservative) was added in to the sanitizer solution and make up in to 100 $\mathrm{ml}$ using double distilled water.

\subsection{In Vitro Evaluation of Transient Bacterial on human palm flora:}

Collection of palm washes samples by Wash/rinse Procedure [7] (Hand washing).

\subsection{Experimental Design:}

A palm washes were taken from five volunteers in whole study period for the evaluation of transient bacterial flora from palms.

\section{Volunteers list}

\begin{tabular}{|c|l|l|c|}
\hline S. No. & $\begin{array}{l}\text { Name of the } \\
\text { volunteers }\end{array}$ & $\begin{array}{c}\text { Volunteers } \\
\text { native }\end{array}$ & $\begin{array}{c}\text { Age of the } \\
\text { volunteers }\end{array}$ \\
\hline S1 & $\begin{array}{l}\text { College } \\
\text { student }\end{array}$ & Punavasal & 25 \\
\hline S2 & $\begin{array}{l}\text { Software } \\
\text { working lady }\end{array}$ & Nanjikottai & 23 \\
\hline S3 & Home maker & Pattukkottai & 26 \\
\hline S4 & Servant maid & Kanni thoppu & 60 \\
\hline S5 & Slum boy & $\begin{array}{l}\text { Mariyamman } \\
\text { koil }\end{array}$ & 5 \\
\hline Pnt
\end{tabular}

The samples were streaked onto nutrient agar.

The inoculated plates were incubated aerobically in an inverted position at $37{ }^{\circ} \mathrm{C}$ for 24 hours. The plates were then observed for the presence of isolated colonies were again sub-cultured on nutrient agar to isolate pure culture. After isolating pure cultures, bacterial isolates were further identified and characterized by Gram staining, and biochemical tests [8]. and identified based on the morphological, physiological and the biochemical characteristics presented in Bergey's Manual of Determination.

\subsection{Screening of anti bacterial activity by agar well diffusion assay}

The agar well diffusion method of Perez et al., 1990 [9] was employed. Mueller Hinton Agar medium was inoculated with the microorganism suspended in sterile water. Once the agar was solidified, it was punched with a six millimeters diameter wells and filled with $25 \mu \mathrm{L}$ of the sample, positive control and negative control. The test was carried out by triplicate. The plaques were incubated at $35 \pm 2{ }^{\circ} \mathrm{C}$ for $24 \mathrm{~h}$. The antimicrobial activity was calculated by applying the expression in $\mathrm{mm}$.

\subsection{In vivo efficacy of Herbal hand sanitizer}

Total of five volunteers with different age groups were involved to evaluate in vivo efficacy of the sample. Total eight palm washes were taken from the volunteers. Control palm washes were taken by use of sterile water only. 


\section{6 a. Bacteriological study [10]}

Point inoculation method was used for viable count of different bacterial flora. Aseptically $10 \mu \mathrm{l}$ palm wash samples were transferred to $90 \mu$ sterile saline $(85 \%)$ solution. Appropriate serial dilutions were made and aseptically $5 \mu \mathrm{l}$ droplets were point inoculated on selective media plates followed by incubation at $37^{\circ} \mathrm{C}$ for $6 \mathrm{hrs}$. Typical colonies showing characteristic coloration were counted and representative colonies were picked up randomly and counter using colony counter.

\subsection{Antioxidant Activity by Power Reducing Assay} [11]

$1 \mathrm{ml}$ of Plant extract was mixed with phosphate buffer (2.5 $\mathrm{ml} \mathrm{0.2} \mathrm{M,} \mathrm{pH} \mathrm{6.6)} \mathrm{and} \mathrm{potassium} \mathrm{ferric} \mathrm{cyanide}$ $(2.5 \mathrm{ml})$. The mixture was incubated at $50^{\circ} \mathrm{C}$ for 20 minutes. A portion $(2.5 \mathrm{ml})$ of trichloroacetic acid $(10 \%)$ was added to the mixture, which was then centrifuged at $3000 \mathrm{rpm}$ for $10 \mathrm{~min}$. The upper layer of solution $(2.5 \mathrm{ml})$ was mixed with distilled water $(2.5 \mathrm{ml})$ and Ferric chloride $(0.5 \mathrm{ml}, 0.1 \%)$ and absorbance measured at $700 \mathrm{~nm}$. Increased absorbance of the reaction mixture indicates stronger reducing power. The activity was compared with ascorbic acid as standard.

\section{Calculation:}

Percentage scavenging activity $=\mathrm{A}_{\text {control }} \mathrm{A}_{\text {test }}$

$$
\times 100
$$

$\mathrm{A}_{\text {control }}$

Where $A_{\text {control }}$ is the absorbance of the control. $A_{\text {test }}$ is the absorbance in the presence of the sample.

\section{RESULTS AND DISCUSSION}

The herbal hand sanitizer was prepared and it was used for evaluate the antimicrobial and antioxidant activity.

\subsection{Identification of Human bacterial flora}

The bacterial flora like Yersinia sp. Proteus sp. Escherichia coli, Klebsiella sp. Salmonella sp. and Pseudomonas sp. were isolated from human palm and identified based on Bergy's manual. In this study, prevalence of gram positive and gram negative bacteria organisms were $66.7 \%$ and $33.3 \%$ respectively (fig: 1). Among Gram negative organisms, Escherichia coli, Klebsiella sp. Salmonella sp. were found to be the most predominant pathogen. Our skin contains large numbers of microorganisms, mainly Gram-positive. Most of the gram positive bacteria are natural flora, which are commonly found on the hands, face and in deep layers of the skin [12, 13]. The goal of hygiene is a sufficient reduction of microbial counts on the skin to prevent crosstransmission of pathogens among humans.

\subsection{Antibacterial Susceptibility Testing}

The antimicrobial activity of herbal hand sanitizer against different pathogens was determined by Agar Well diffusion method. The sample hand sanitizer possessed more antibacterial effective against isolated microorganisms with the inhibition zone ranging from 15-30.8 mm. More activity was found in Yersinia sp.> Proteus sp $>$ Salmonella sp.> Klebseilla sp.> Pseudomonas sp. $>$ E.coli. Aloe vera used for its moisturizing activity in many cosmetics [6]. Plants are rich in potential secondary metabolites, such as flavonoids, tannins alkaloids polyphenols ext. These compounds have diverse biological activity including antibacterial activity [14]. Most of the polyphenols are extracted in the methanol [15]. The results suggested that herbal extracts in mixture giving higher activity than the individual extracts. The combination of the antibacterial compounds from different plant extracts may show synergistic effect enhancing their antimicrobial activity.

Mithun A. Thombare [16] et al. 2015 observed that the alcohol based herbal hand sanitizer (at concentration $400 \mu \mathrm{g} / \mathrm{ml}$ ) showed greater inhibition zones against bacterial species Escherichia coli, Pseudomonas aeruginosa, Bacillus subtilis and Staphylococcus aureus in comparison to commercially available hand sanitizer.

\section{Microbial Load}

Microbial load was analysed before applying sanitizer and after applying of herbal based sanitizer. The result showed that microbial load was considerably low after applying herbal hand sanitizer. Highest reduction was observed in college student and slum boy with 75 and $50 \%$ respectively after the application of herbal hand sanitizer. Many studies have been done earlier in view of evaluation of total transient microflora of hands. Staphylococci especially coagulase -negative S.aureus were found to be the dominant part of 
transient hand microflora [17]. Colonization of health care worker hands with S.aureus has been described to range between 10 to $76.3 \%$ and transient flora varies considerably from person to person [18]. It was concluded that the herbal based sanitizer had potential to control and prevent the over population of bacterial flora in the palm.

Kavatheker et. al. (2004)[19], reported that pure herbal hand sanitizers were found to be more effective in reducing the total microbial load. Alcohol rubs are approximately 100 times more effective against viruses than any form of hand washing [20].Sanitizers offer numerous advantages over non-alcoholic hand disinfectants as, rubbing sanitizers onto both hands \&until it completely evaporate, usually requires only 15 to 30 seconds. Whereas vigorous friction, rinsing with water, and drying with a towel are not needed like hand disinfectants or soaps [21].

In vitro Antioxidant activity of Herbal hand sanitizer

A concentration dependent scavenging activity was observed in herbal hand sanitizer with maximum activity of $49.4 \%$ achieved in the highest tested concentration at $10 \mathrm{mg} / \mathrm{ml}$ (fig 3). The sample had relatively higher reducing power due to the presence of high bioactive compounds which was present in selected medicinal ingredients and it has been attributed with properties like free radical scavenging, anthelmintic, antimicrobial, antiinflammatory and analgesic etc. which are widely used in cosmetic, and pharmaceutical industries, natural antioxidants $[22,23,24]$. Hence, it could have promising skin care properties, can able to protect the human body from free radicals.

\section{SELECTIVE PLATING}

The test organisms were confirmed by plating them in selective medium and the results were observed and showed in table. 2
Table 2: List of selective medium and test organisms

\begin{tabular}{|c|l|l|}
\hline S. No. & \multicolumn{1}{|c|}{ Test Organism } & \multicolumn{1}{|c|}{ Medium used } \\
\hline 1 & Yersinia sp. & Yersenia agar \\
\hline 2 & Proteus sp. & Macconkey agar \\
\hline 3 & Escherichia coli & Brilliant green agar \\
\hline 4 & Klebsiella sp. & EMB agar \\
\hline 5 & Salmonella sp. & SS agar \\
\hline 6 & Pseudomonas sp. & Macconkey agar \\
\hline
\end{tabular}

Table: 3. Microbial load before and after applying herbal hand sanitizer:

\begin{tabular}{|l|c|c|c|}
\hline Volunteers & $\begin{array}{c}\text { Load } \\
\text { before } \\
\text { applying } \\
\text { sanitizer }\end{array}$ & $\begin{array}{c}\text { Load } \\
\text { after } \\
\text { applying } \\
\text { sanitizer }\end{array}$ & $\begin{array}{c}\text { Percentage } \\
\text { of } \\
\text { reduction }\end{array}$ \\
\hline $\begin{array}{l}\text { College } \\
\text { student }\end{array}$ & $4 \times 10^{3}$ & $3 \times 10^{3}$ & 75 \\
\hline $\begin{array}{l}\text { Software } \\
\text { working } \\
\text { lady }\end{array}$ & $6 \times 10^{3}$ & $2 \times 10^{3}$ & 33 \\
\hline $\begin{array}{l}\text { Home } \\
\text { maker }\end{array}$ & $5 \times 10^{3}$ & $2 \times 10^{3}$ & 40 \\
\hline $\begin{array}{l}\text { Servant } \\
\text { women }\end{array}$ & $7 \times 10^{3}$ & $3 \times 10^{3}$ & 43 \\
\hline Slum boy & $8 \times 10^{3}$ & $4 \times 10^{3}$ & 50 \\
\hline
\end{tabular}

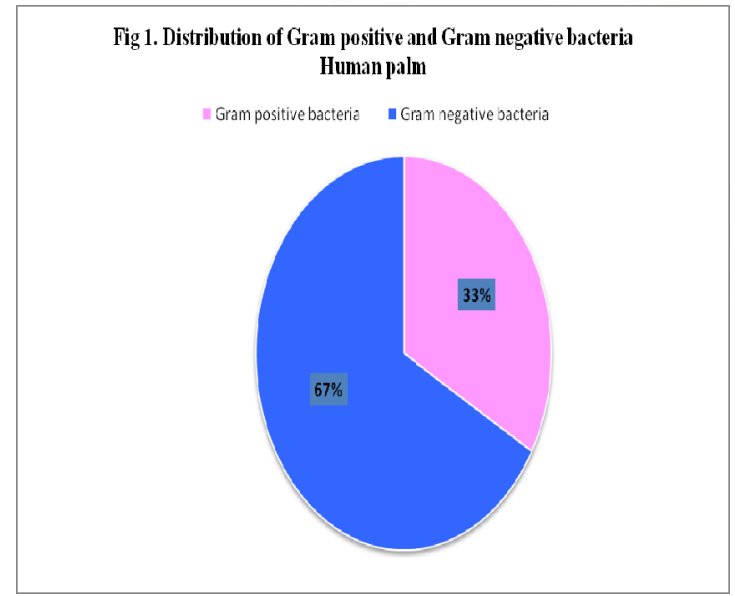


International Journal of Trend in Scientific Research and Development (IJTSRD) ISSN: 2456-6470

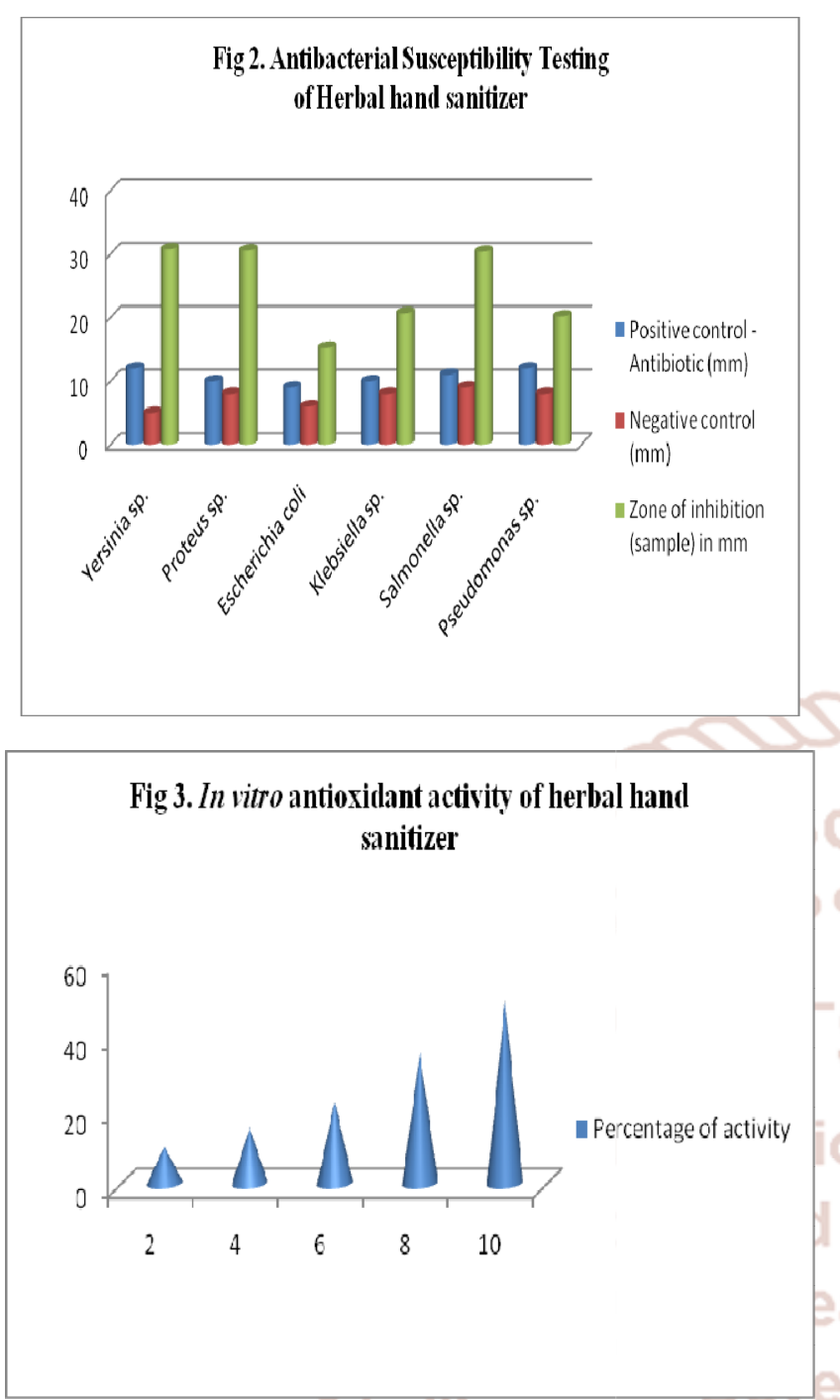

\section{CONCLUSION}

Hand hygiene is a vital principle exercise in the prevention, control, and reduction of healthcare acquired infections. Proper hand washing and drying methods prevent the chain of transmission of deadly pathogens from the contaminated site to other parts of the body. Hand sanitization is the paramount aid in preventing nosocomial infections caused by different opportunistic microorganisms .In this present study, results showed that the herbal sanitizer has antimicrobial property, antioxidant activity, and considerable microbial load. When compare to alcohol based hand sanitizers, herbal hand sanitizer is more effective against microbes, non toxic, formulate hand soft and makes the hand hygienic. The further study will be conducted for evaluation of bioactive compounds in herbal hand sanitizer responsible for medicinal properties and its shelf life time. Thus, there is immense potential in establishing the use of antimicrobial herbal products as a measure to control the multidrug resistant microbes as well as to check their spread through hands from one geographical region to another.

\section{Acknowledgment}

I am grateful to Tamilnadu State Council for Science and technology, for their financial assistance and support to this project.

\section{Reference}

1) Ravi K, Pratibha MD, Kolhapure SA. Evaluation of the antimicrobial efficacy and safety of Pure Hands as a hand sanitizer: Indian Journal of Clinical Practice, 2005; 15(10): 19-27.

2) WHO guidelines on hand hygiene in health care 2009. First global patient safety challenge - clean care is safer care. Geneva.

3) Mashood AS, Satheesh B N, Mohd. G Formulation, Evaluation and Antibacterial Efficiency of Herbal Hand Wash Gel Int. J. Pharm. Sci. Rev. Res., 2014; 25(2): 23, 120-124.

4) Kole PL, Jadhav HR, Thakurdesai P, Nagappa AN. Cosmetic potential of Herbal extracts. Nat Prod Rad. 4;2005:3 15-321.

5) Milovanović M, Banjac N, Radović BV. Functional food: rare herbs, seeds and vegetable oils as sources of flavors and phytosterols. J Agric Sci. 54(1);2009:80-93.

6) "Raskin I, Ribnicky DM, Komarnytsky S, Ilic N, Poulev A, Borisjuk N, Brinker A, Moreno DA, Ripoll C, Yakoby N, O’Neal JM, Cornwell T, Pastor I, Fridlender B. Plants and human health in the twenty-first century. Trends Biotechnol. 2002;20(12):522-532.

7) Monique Courtenay, Lina Ramirez, Beth Cox, Inyee Han, Xiuping Jiang, Paul Dawson (2005). Effects of various hand hygiene regimes on removal and/or destruction of Escherichia coli on hands. Volume5, Issue2-4. Pages 77-84.

8) Ekrakene T and Igeleke CL(2007). Microorganis ms associated with public mobile phones along be nin- sapele express way. J. Appl. Sci. Res. ;3(12):2009-12.

9) Perez, C.; Pauli, M. and Bazerque, P. (1990). An antibacterial assay by agar well diffusion method. Acta Bio Et Med Exp. 15, 113-115. 
10) Miles, AA; Misra, SS; Irwin, JO (Nov 1938). "The estimation of the bactericidal power of the blood". The Journal of hygiene. $38(6)$ : $732-49$.

11) Yildirin A, Oktay $M$, and Bilalogu V. The Antioxidant activity of the leaves of Cyclonia vulgaris. Turkish Journal of Medical Science 2001; 31: 23-27.

12) Cinco $M$, Banfi $E$ and Tubaro A. A microbiological survey on the activity of a hydroalcoholic extract of madhuca indica. Int $\mathrm{J}$ Drug Res., 1983; 4: 145-151.

13) Jay Ram Patel, Reenu Yadav, Vidhi Guha, Udit N. Soni and Abhishek Sharma 2016. Formulation and evaluation of herbal hand wash. World Journal of Pharmacy and Pharmaceutical Sciences. Vol 5, Issue 3, 675-683.

14) Ghasemi E, Golshahi H, Ghasemi E, Mehranzade E (2011). Antibacterial activity of Ocimum sanctum extract against $E$. coli, $S$. aureus and $P$. aeruginosa. Clin Biochem.;44(13): S352.

15) Dutra RC, Leite MN, Barbosa NR (2008). Quantification of phenolic constituents and antioxidant activity of Pterodon emarginatus vogel seeds. Int J Mol Sci.;9:606-614.

16) Larson E.; Mayur K. \& Laughon B.A. (1988): Influence of two hand washing frequencies on the reduction in colonizing flora with three hand washing products used by health care personnel. Am.J. Infect. Control 17(2): 83-8.

17) Ayliffe G. A.; Babb J. R. \& Quoraishi A.H. (1978): A test for hygienic hand disinfection. J.Clin.Pathol.;31: 923-28.

18) Kavathakar M.; Bhardwaj R. \& Kolhapure A. S. (2004): Evaluation of clinical efficacy \& safety of pure hands in hand hygiene. Med. Update; 12(3):49-55.

19) Mondal Sunanda, Kolhapure S.A., Evaluation of the antimicrobial efficacy and safety of Pure Hands herbal hand sanitizer in hand hygiene and on inanimate objects. The Antiseptic. 2004;101(3): 112-120.

20) Pittet D, Mourouga P, Perneger TV. Compliance with handwashing in a teaching hospital: infection control program. Ann Intern Med. 1999; 130: 126130.
21) Moure A, Cruz JM, Franco D, Domínguez JM, Sineiro J, Domínguez H, Núñez MJ, Parajo JC. 2001. Natural antioxidants from residual sources. Food Chem. 72:145-171.

22) Rubilar M, Pinelo M, Shene C, Sineiro J, Nuñez MJ. 2007. Separation and HPLC-MS identification of phenolic antioxidants from agricultural residues: almond hulls and grape pomace. J Agric Food Chem. 55:10101-10109.

23) Miliauskas G, Venskutonis PR, van Beek TA. 2004. Screening of radical scavenging activity of some medicinal and aromatic plant extracts. Food Chem. 85:231-237.

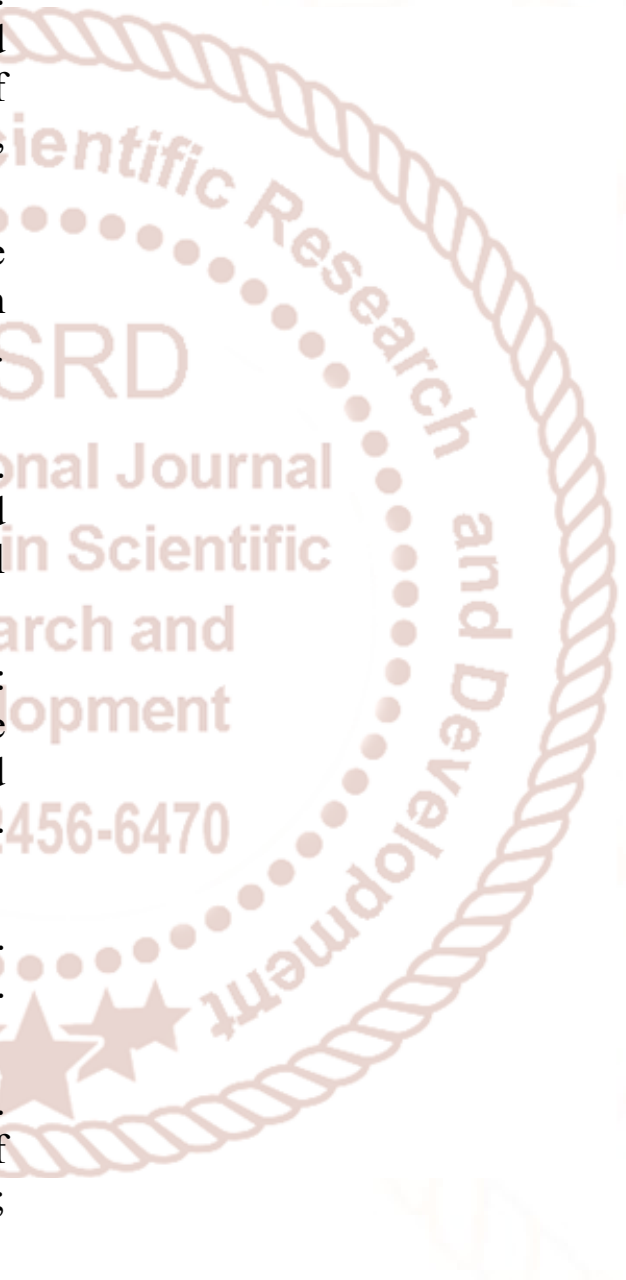

